For

\title{
Direct Observations of the Occlusion of Soil Organic Matter within
}

9

\section{Calcite}

Jialin Chi, ${ }^{\dagger}$ Wenjun Zhang,,${ }^{*} \dagger$ Lijun Wang,,${ }^{*} \dagger$ and Christine V. Putnis ${ }^{\dagger}, \S$

${ }^{\dagger}$ College of Resources and Environment, Huazhong Agricultural University, Wuhan 430070, China

*Institut für Mineralogie, University of Münster, 48149 Münster, Germany ${ }^{\S}$ Department of Chemistry, Curtin University, Perth 6845, Australia

10 pages; 2 tables; 11 figures

SI tables (S2)

SI figures (S2-S10) 
23 Table S1. Solution composition used in the oxalate-containing experiments.

\begin{tabular}{cccc}
\hline IS & $\mathrm{pH}$ & {$\left[\mathrm{Ca}^{2+}\right](\mathrm{mM})$} & {$\left[\mathrm{C}_{2} \mathrm{O}_{4}{ }^{2-}\right](\mathrm{mM})$} \\
\hline 0.11 & 8.3 & 0.17 & 0.1
\end{tabular}

24

25 Table S2. The supersaturation of two calcium oxalate phases.

\begin{tabular}{cc}
\hline phase & $\sigma$ \\
\hline calcium oxalate monohydrate $(\mathrm{COM})$ & -0.240 \\
calcium oxalate dihydrate (COD) & -0.484 \\
\hline
\end{tabular}

26
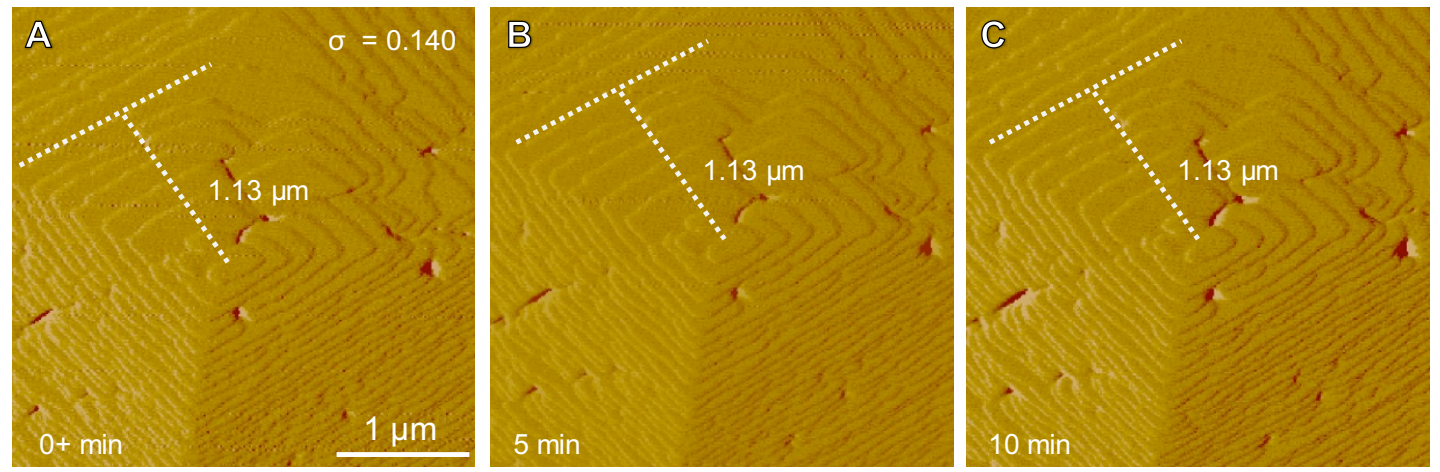

28 Figure S1. Time-resolved AFM images showing that the same step does not move in

29 a near-equilibrium supersaturated solution $(\sigma=0.140, \mathrm{pH} 8.3)$. 

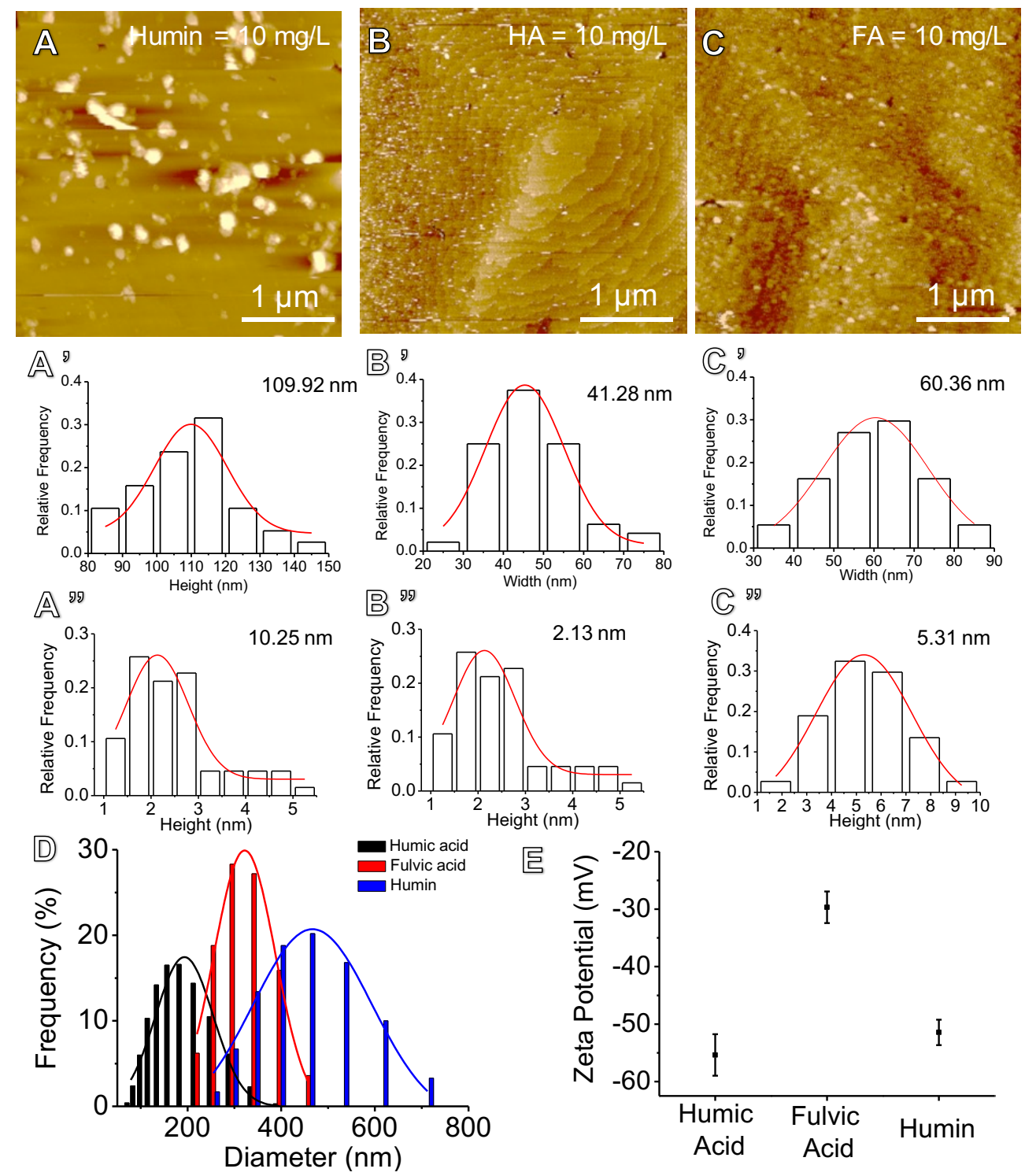

Figure S2. (A-C) AFM images (contact mode) after $20 \mathrm{~min}$ of injection of a supersaturated solution $(\sigma=0.140, \mathrm{pH} 8.3)$ in the presence of (A) humin, (B) humic acid (HA), or (C) fulvic acid (FA). The size distributions of the aggregated (A') humin, (B') HA, and (C') FA particles adsorbed on the calcite surface with an average width of $109.92 \mathrm{~nm} \pm 2.08 \mathrm{~nm}(n=40), 41.28 \pm 1.06 \mathrm{~nm}(n=40)$ and $60.36 \pm 0.48 \mathrm{~nm}(n=$ $40)$, respectively, and with heights of $10.25 \pm 0.31 \mathrm{~nm}(n=50), 2.13 \pm 0.11 \mathrm{~nm}(n=$ $40)$ and $5.31 \pm 0.06 \mathrm{~nm}(n=40)$, respectively, measured from AFM in situ images. (D) The size distribution of three humic substances at $10 \mathrm{mg} / \mathrm{L}$ in a near-equilibrium supersaturated solution with respect to calcite $(\sigma=0.140, \mathrm{pH} 8.3)$ measured by DLS. The average diameters of HA, FA and humin are $193.24 \pm 4.55 \mathrm{~nm}(n=4), 321.99 \pm$ 

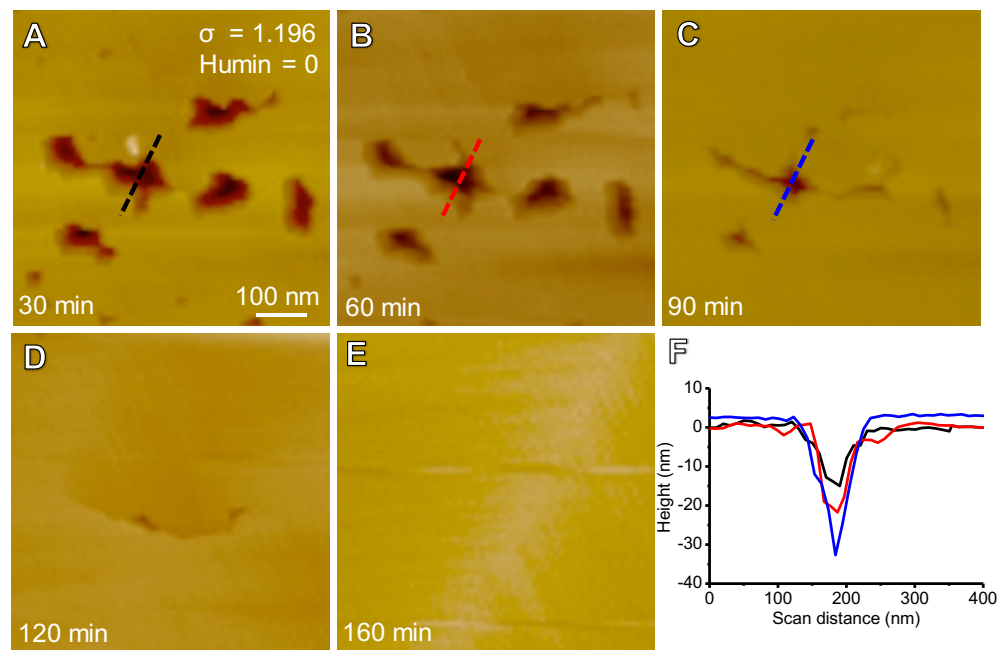

46

47 Figure S3. AFM images of the detailed process of the cavities closing as shown in Figure 1. (A-E) The cavities were gradually closed, indicating the presence of internal cavities. (F) The depth of the cavities measured along the dashed lines in A-C The cavities were gradually deepened from $14 \mathrm{~nm}$ in (A) to $36 \mathrm{~nm}$ in (C). 

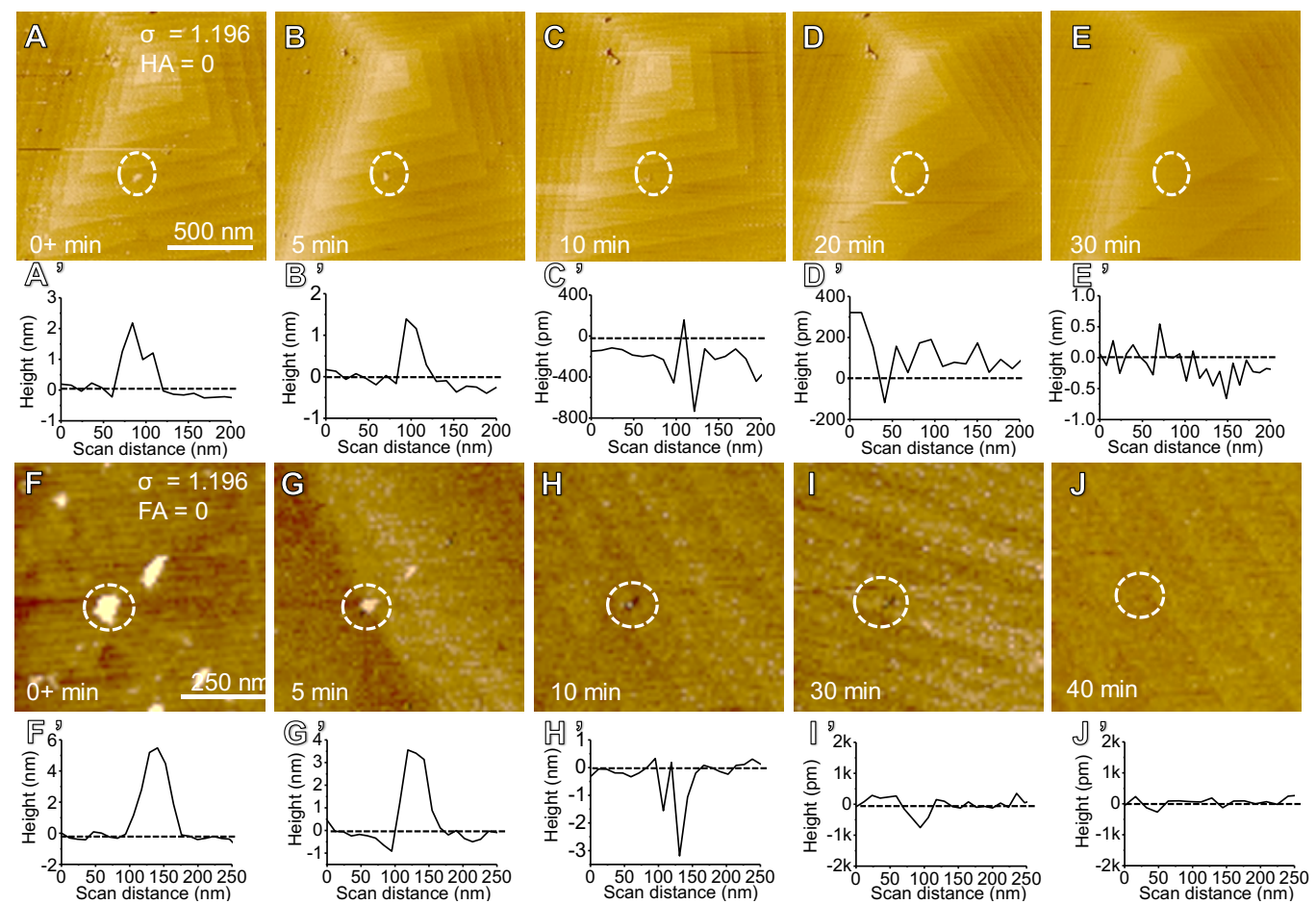

Figure S4. Incorporation dynamics of humic acid and fulvic acid within calcite. A time sequence of AFM height images showing a detailed process of (A-E) humic acid (HA) particles or (F-J) fulvic acid (FA) particles buried into calcite during growth by step advancement in a supersaturated solution $(\sigma=1.196, \mathrm{pH} 8.3)$. (A'-J') Height profiles of humic acid or fulvic acid particles in the dotted circles in (A-J) showing corresponding height changes during the occlusion process.
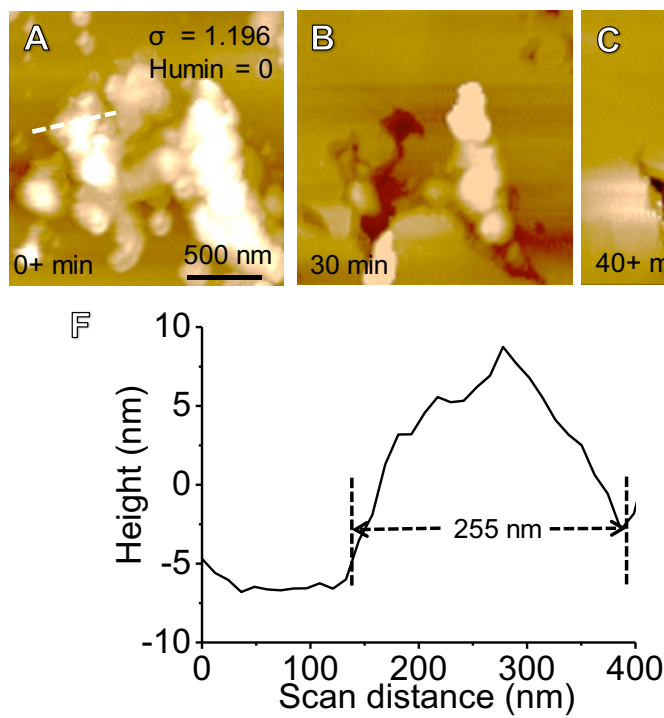
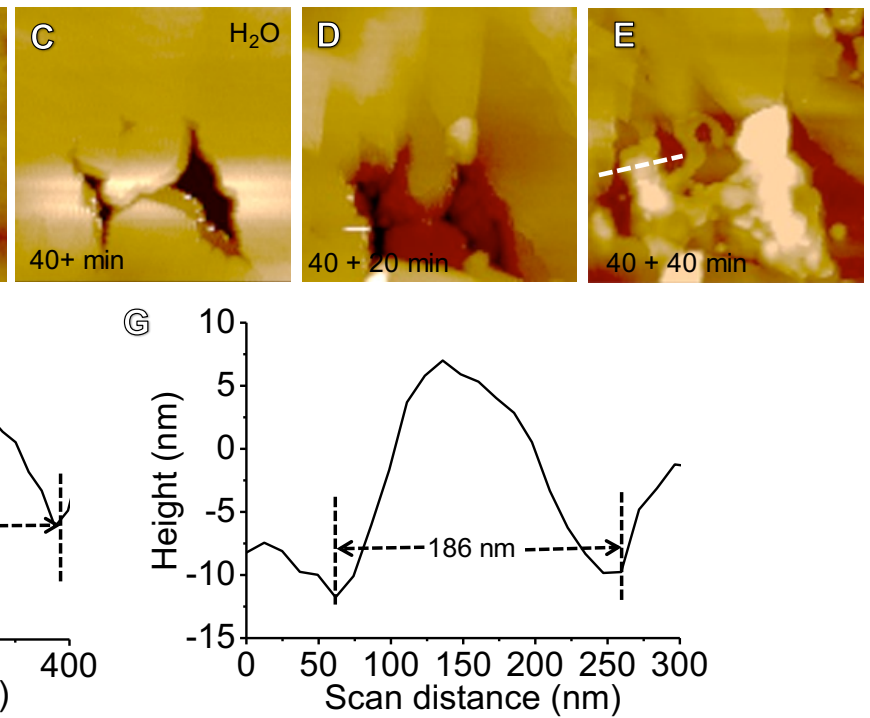

4

Figure S5. (A-C) A time sequence of AFM height images showing humin particles buried into the calcite in a supersaturated solution $(\sigma=1.196, \mathrm{pH} 8.3)$. (D, E) Upon introduction of ultrapure water, the same area of calcite rapidly dissolves and the buried particles are exposed. (F-G) The width of the same particles measured along the white dashed lines in (A and $\mathrm{E}$ ) decreases after the occlusion is reexposed.

Figure S6. SEM image of the precipitated particles formed on the calcite surface in a 67 solution supersaturated with respect to calcite $(\sigma=0.140)$ in the presence of $100 \mu \mathrm{M}$ 8 phytate for $12 \mathrm{~h}$. (Inset) EDX spectrum showing that the particles consist of $\mathrm{Ca}, \mathrm{O}, \mathrm{C}$, 9 P. 

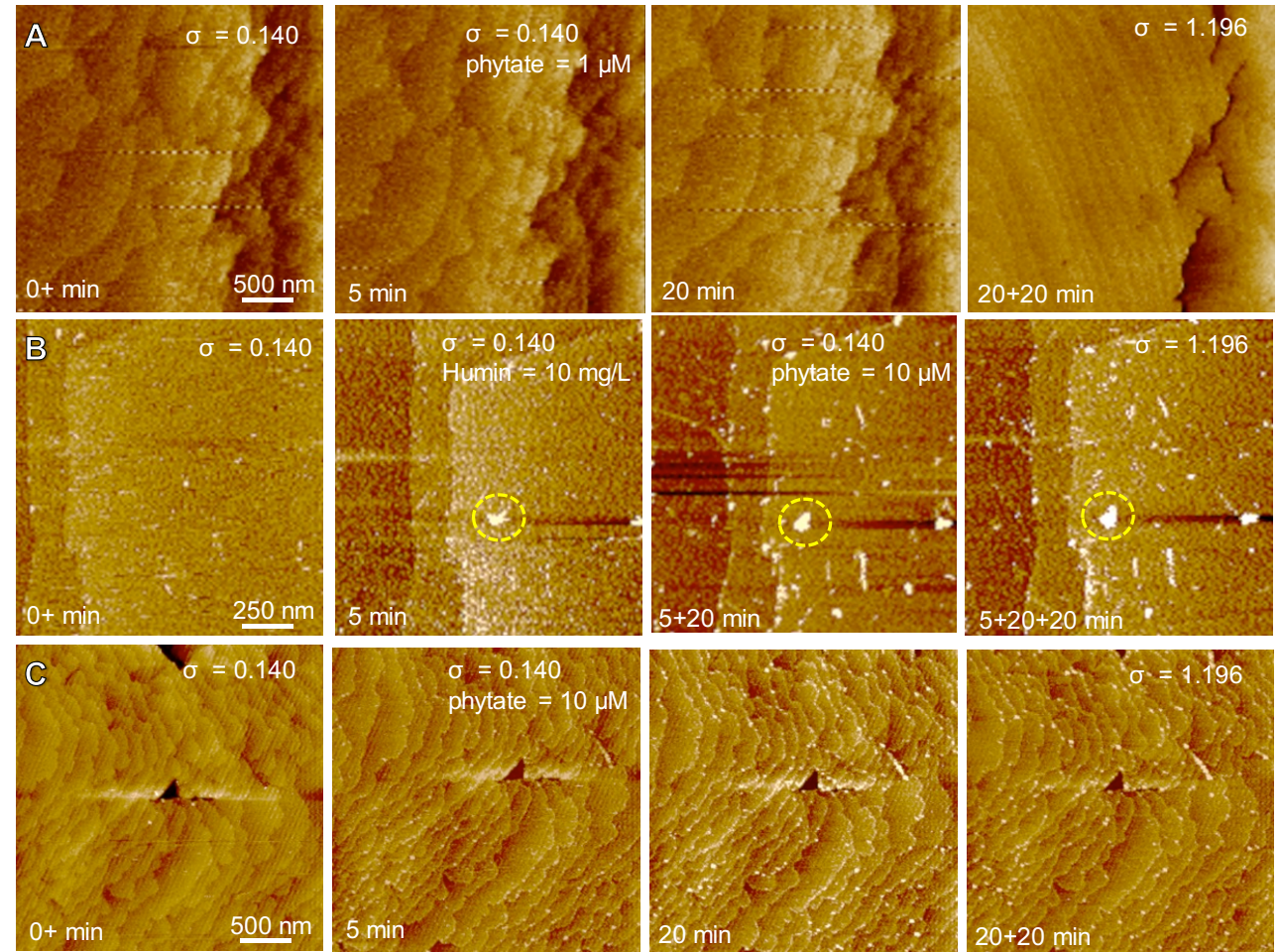

Figure S7. (A) AFM images showing that no new particles are formed in a supersaturated solution at $\sigma=0.140$ in the presence of $1 \mu \mathrm{M}$ phytate and the steps could advance in a highly supersaturated solution $(\sigma=1.196, \mathrm{pH} 8.3)$. (B) The effect of phytate $(10 \mu \mathrm{M})$ on the occlusion process. After the introduction of $10 \mu \mathrm{M}$ phytate in a supersaturated solution $(\sigma=0.140, \mathrm{pH} 8.3)$, newly formed particles are rapidly adsorbed along the step edges to inhibit the burial of humin in high supersaturation calcite solution ( $\sigma=1.196, \mathrm{pH} 8.3$ ). (C) In situ AFM height images showing the adsorption of particles on the step edges of a growing spiral in a supersaturated solution $(\sigma=0.140, \mathrm{pH} 8.3)$ in the presence of $10 \mu \mathrm{M}$ phytate; the step growth is inhibited and cannot advance in a highly supersaturated solution $(\sigma=1.196, \mathrm{pH} 8.3)$. 

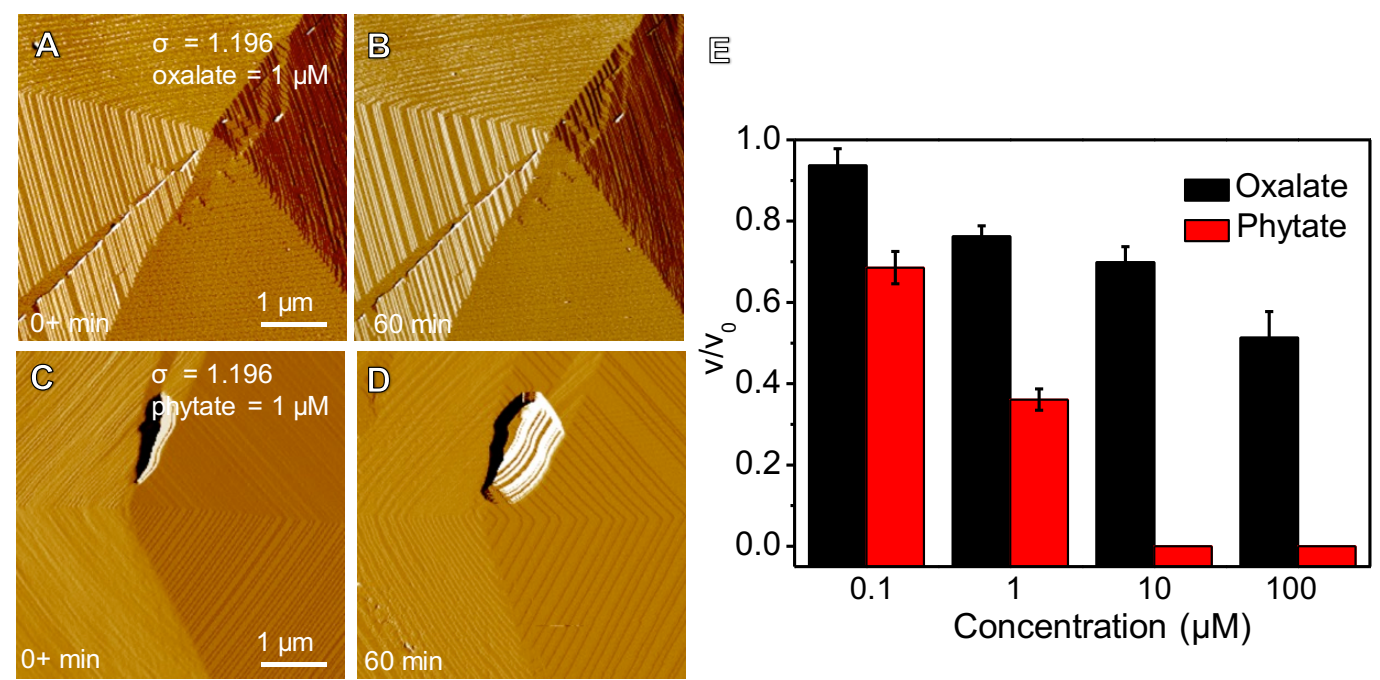

Figure S8. (A-B) AFM deflection images in contact mode of calcite hillocks grown in indicating the inhibitory effect of phytate.
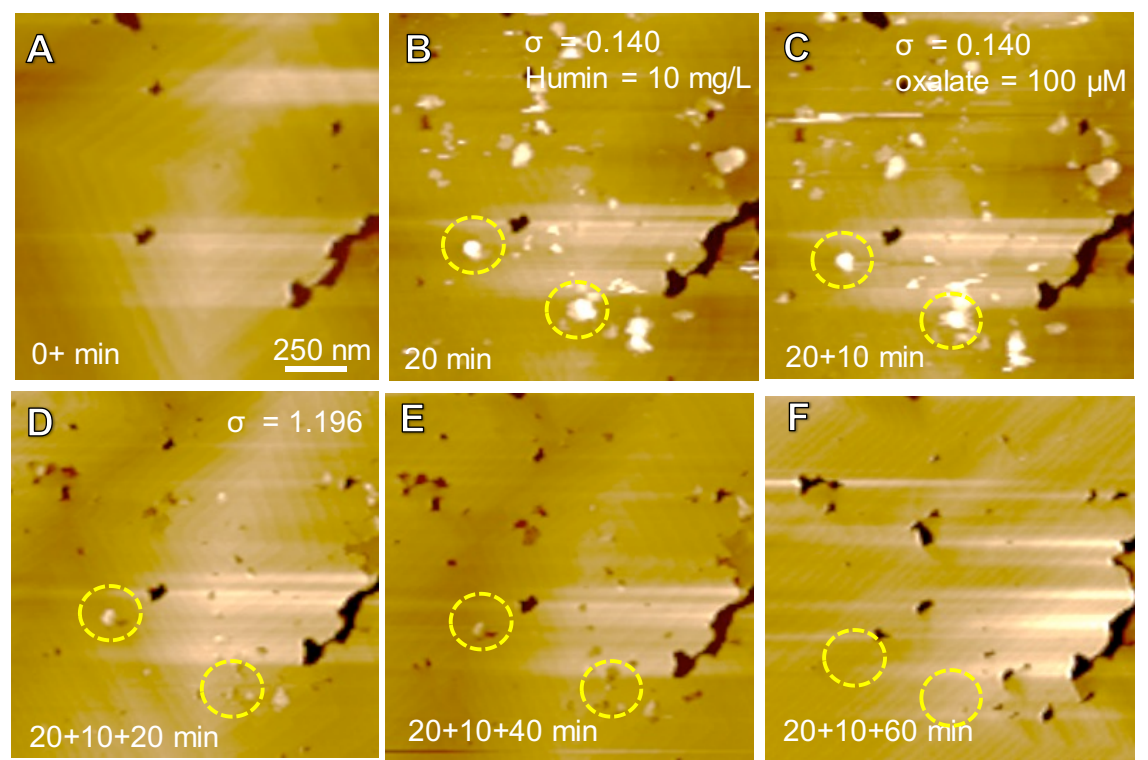

Figure S9. The effect of oxalate on the occlusion process. (A, B) AFM images of humin adsorbed on a calcite surface to form particles (about $10 \mathrm{~nm}$ in height) after 20 min of exposure in a supersaturated solution $(\sigma=0.140, \mathrm{pH} 8.3)$ in the presence of 10 

oxalate in a supersaturated solution $(\sigma=0.140, \mathrm{pH} 8.3)$. (D-F) Following 60 min of injecting a highly supersaturated solution $(\sigma=1.196, \mathrm{pH} 8.3)$, the adsorbed humin particles are gradually incorporated into a calcite spiral.
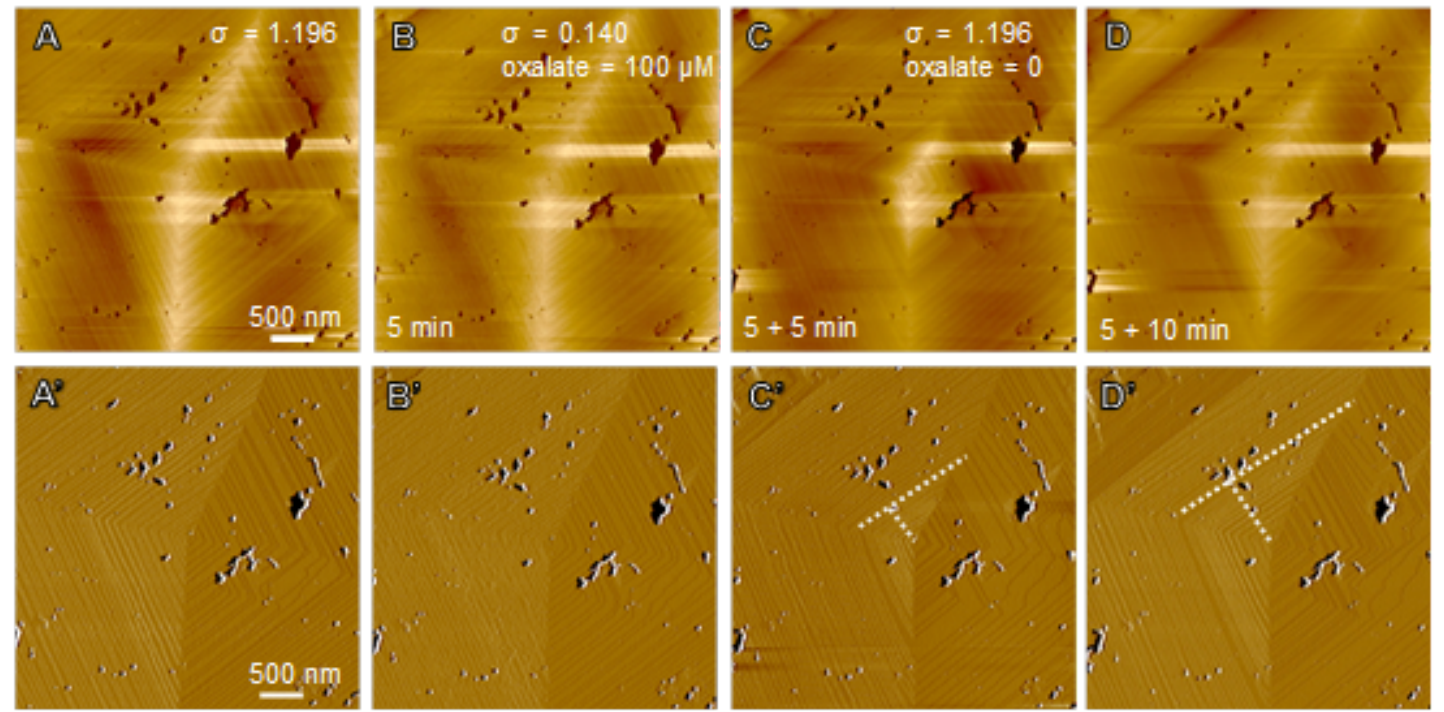

Figure S10. AFM (A, B) height and (A', B') deflection images illustrating that no new particles are formed in a supersaturated solution at $\sigma=0.140$ in the presence of100 $\mu \mathrm{M}$ oxalate. AFM (C, D) height and (C', D') deflection images showing that the spiral growth recovers with step advancement (indicated by the white dotted lines in C' and D' after injecting a high supersaturation solution $(\sigma=1.196)$ without oxalate. 

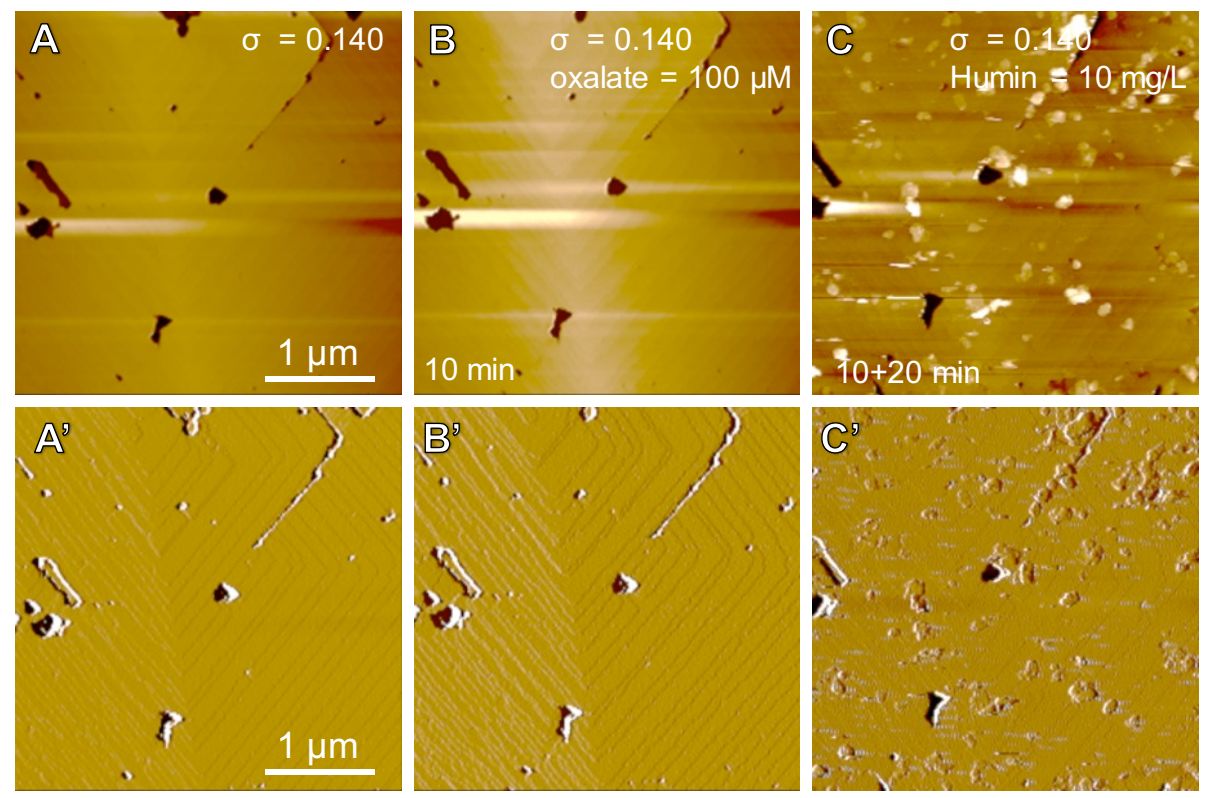

104 Figure S11. AFM (A, B) height and (A', B') deflection images of a calcite surface in 105 a supersaturated solution $(\sigma=0.140, \mathrm{pH} 8.3)$ with $100 \mu \mathrm{M}$ oxalate. (C, C') Following $10620 \mathrm{~min}$ of injection of $10 \mathrm{mg} / \mathrm{L}$ humin, the adsorbed particles do not exhibit obvious 107 differences in the presence and absence of oxalate, suggesting that oxalate molecules 108 do not promote the adsorption of humin particles. 